\title{
Primary ovarian pregnancy: rare site of ectopic gestation
}

\author{
Neha R. Goyal*, Swati G. Kapsikar, Binti R. Bhatiyani, Pradip R. Gaikwad
}

Department of Obstetrics and Gynecology, esi pgimsr, Andheri - East, Mumbai, Maharashtra, India

Received: 17 September 2015

Revised: 26 September 2015

Accepted: 29 October 2015

\section{*Correspondence:}

Dr. Neha R. Goyal

E-mail: nehagoyal@86yahoo.co.in

Copyright: (C) the author(s), publisher and licensee Medip Academy. This is an open-access article distributed under the terms of the Creative Commons Attribution Non-Commercial License, which permits unrestricted non-commercial use, distribution, and reproduction in any medium, provided the original work is properly cited.

\begin{abstract}
Ovarian pregnancy is one of the rarest varieties of ectopic gestation. Intrauterine devices have evolved as probable risk factor. It is often difficult to distinguish it from tubal ectopic clinically. Diagnosis is generally retrospective during surgery with confirmation by histopathological examination. Hereby we are presenting a case of primary ovarian pregnancy in a multiparous female of reproductive age group using cu-t as contraception presented with acute abdomen managed by conservative surgery and diagnosis confirmed by histopathological examination.
\end{abstract}

Keywords: Primary ovarian ectopic, Partial ovariectomy, Transvaginal ultrasound

\section{INTRODUCTION}

Ovarian ectopic pregnancy is a rare form of ectopic pregnancy representing $0.3-3 \%$ of all ectopic pregnancies. ${ }^{1}$ Its diagnosis still continues to challenge the practicing clinicians. Ovarian pregnancy was first reported by Saint Maurice de Perigot in 1682 and since then many cases have been reported in the literature. Hertig estimated that ovarian pregnancy occurs in 1 in $25,000-40,000$ pregnancies. $^{2}$

\section{CASE REPORT}

24 years old P2L2 MTP1 woman presented to emergency department with complaints of 40 days amenorrhoea, slight vaginal bleeding with abdominal pain and giddiness since last 3 days. Her previous menstrual cycles were regular. She has history of using $\mathrm{Cu}-\mathrm{t}$ as contraception for the last 2 years. She has no significant medical or surgical history. On physical examination there was minimal pallor, her vitals were in normal range. On per abdomen examination, abdomen was soft and mild tenderness was present in left iliac fossa. On per speculum examination $\mathrm{Cu}-\mathrm{t}$ thread was seen along with slight vaginal bleeding. On bimanual pelvic examination normal size anteverted uterus with minimal cervical motion tenderness in addition to left forniceal tenderness and fullness was found. $\mathrm{Cu}-\mathrm{t}$ was removed under all aseptic precautions. Her urinary pregnancy test was positive and her serum B-hcg was found to be $812 \mathrm{mUI} /$ $\mathrm{ml}$. Her blood investigations revealed $\mathrm{Hb} 9.5 \mathrm{gm} \%$ and other routine investigations were in normal range. Ultrasonographic examination showed empty uterus with approx. $2 * 3 \mathrm{~cm}$ hyperechoic mass with central hypoechoic shadow in left adnexa. Presumptive diagnosis of ruptured ectopic was made and patient was prepared and taken for emergency exploratory laparotomy.

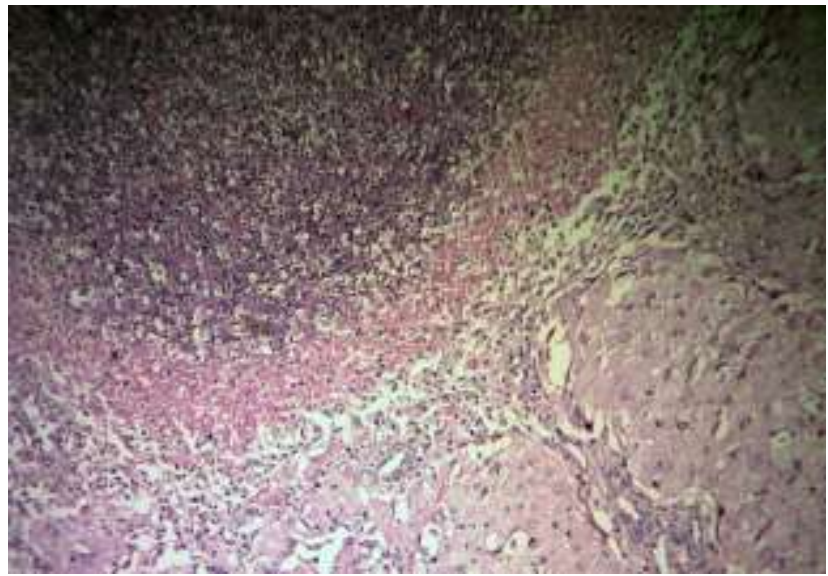

Figure 1: Diagnosis of ovarian ectopic gestation. 
On exploratory laparotomy, $100 \mathrm{cc}$ hemoperitoneum was suctioned. Left ovarian hemorrhagic mass $(2 * 3 \mathrm{~cm})$ was present with completely normal left sided fallopian tube, normal uterus and normal right adnexa. Left sided wedge resection of hemorrhagic mass was done while maintaining complete hemostasis and specimen sent for histopathological examination. On histopathological examination diagnosis of ovarian ectopic gestation was confirmed with presence of necrotic chorionic villi and a corpus luteum. Her postoperative period was uneventful and patient was discharged on $7^{\text {th }}$ day.

\section{DISCUSSION}

The etiology of ovarian pregnancy is unknown, specifically as the usual causative factors - pelvic inflammatory disease and pelvic surgery - implicated in tubal ectopic seems to be uninvolved. There appears to be a link to the intrauterine device. However it cannot be concluded that this is a causative as it could be that IUDs prevent other but not ovarian pregnancies. In a case series by Raziel et al, ${ }^{3} 18$ out of 20 patients with ovarian ectopic had IUD.

The symptoms and physical findings such as abdominal pain, menstrual irregularity, vaginal bleeding, palpable adnexal mass or hypotensive collapse, are similar to those of tubal pregnancy, hemorrhagic corpus luteum or a ruptured ovarian cyst. The increased use of transvaginal ultrasound has resulted in more frequent diagnosis of unruptured ovarian pregnancy. ${ }^{4}$ Ultrasonographically, the appearance of ovarian pregnancies varies as widely as that seen in tubal pregnancies and has been summarized recently. ${ }^{5}$ The decisive ultrasonographic characterstics for discrimination from a tubal pregnancy in the first trimester are the visualization of embryonic structures in an amniotic cavity within the ovary.

Early diagnosis is important so that conservative management could be opted. Medical management in the form of methotrexate has not been evaluated as a correct clinical or radiological diagnosis is rarely certain in these cases. ${ }^{6}$ Conservative surgery in the form of ovarian wedge resection or ovarian cystectomy can be performed safely if the lesion is small. However, in larger lesions with active bleeding, oophorectomy should be done. The increased vulnerability and vascularity of the ovary constitutes a higher risk of rupture with serious bleeding, and possibly, hemorrhagic shock. This considerably complicates manipulation of the ovary for the diagnosis and therapy during the operation, and even the localization of the pregnancy in cases without rupture may be difficult.

Because of the insufficiency of macroscopic evaluation and the risk of misdiagnosis for conditions such as a haemorrhagic corpus luteum or a ruptured bleeding lutein cyst, histological examination is warranted. The case should fulfil the classical anatomical and histological criteria suggested by spiegelberg:
1. The fallopian tubes with their fimbriae should be intact and separate from the ovary.

2. The gestational sac should occupy the normal position of the ovary.

3. The gestation should be connected to the uterus by the ovarian ligament.

4. Ovarian tissue must be present in the specimen attached to the gestation sac. ${ }^{7}$

Due to coagulation artefacts and the small tissue volumes available, it may be difficult to find ovarian tissue around the gestational sac microscopically. A modification of the fourth postulate of speigelberg is the detection of chorionic villi without concurrent detection of an intact ovarian parenchyma for diagnosis and is sufficient today for a selective laparoscopic biopsy. ${ }^{8}$

\section{CONCLUSIONS}

Ovarian ectopic is a rare variant of ectopic pregnancy whose preoperative diagnosis is still a medical challenge. Transvaginal Sonography can be a valuable tool in identifying an ovarian pregnancy. Management with laparoscopy or laparotomy is required in all cases and in almost all cases conservative surgery can be opted since implantation is usually superficial. ${ }^{9}$ Hence it can be concluded that possibility of ovarian ectopic should be keep in differential diagnosis in a female of reproductive age group presenting with acute abdomen.

\section{Funding: No funding sources \\ Conflict of interest: None declared \\ Ethical approval: Not Required}

\section{REFERENCES}

1. Salas Valien JS, Rayero Alvarez MP, Gonzalez Moran MA, Garcia Merayo M, Nieves Diez C. Ectopic ovarian pregnancy. An Med Intern 1995;12:192-4.

2. Gerin-Lojoie L. Ovarian pregnancy. Am j Obstet and Gynecol. 1951;62(4):920-9.

3. Raziel A, Golan A, Pansky M. A report of twenty cases in one institution. Am J Obstet Gynecol. 1990;163:1182-5.

4. Sidek S, Lai SF, Lim-Tan SK, Primary ovarian pregnancy current diagnosis and management. Singapore Med. 1994;35(1):71-3.

5. Hönigl W, Reich O. Vaginal ultrasound in ovarian pregnancy. Ultraschall med. 1997:18(5):233-6.

6. Nadarajah S, Sim LN, Loh SF. Laparoscopic management of ovarian pregnancy. Singapore Med J. 2002;43(2): 95-6.

7. Spiegelberg O. Zur Kasuistik der Oarialschwangerschaft. Arch Gynaekol. 1878;13:739.

8. Cehelmow D, Gate E, Penzias AS. Laproscopic diagnosis and methotrexate treatment of ovarian pregnancy: acase report. Fertil steril. 1994;62:87981 . 
9. Koo YJ, Choi HJ, Im KS, Jung KS, Kwon YS. Pregnancy outcomes after surgical treatment of ovarian pregnancy. International Journal of Gynecology \& Obstetrics. 2011;114(2):97-100.
Cite this article as: Goyal NR, Kapsikar SG,

Bhatiyani BR, Gaikwad PR. Case report of a primary ovarian ectopic pregnancy. Int J Reprod Contracept Obstet Gynecol 2015;4:2062-4. 